\title{
Delay in Hospital Admission of Patients with Cerebral Vein and Dural Sinus Thrombosis
}

\author{
José M. Ferro ${ }^{a}$ M.G. Lopes ${ }^{b}$ M.J. Rosas ${ }^{c} \quad$ J. Fontes ${ }^{d}$ for the \\ VENOPORT Investigators
}

Departments of Neurology at ${ }^{\mathrm{a}} \mathrm{Hospital}$ Santa Maria, Lisboa, ${ }^{\mathrm{b} H o s p i t a l}$ Santo António, ${ }^{\mathrm{c} H o s p i t a l ~ S a ̃ o ~ J o a ̃ o, ~}$ Porto, and ${ }^{\mathrm{d}}$ Hospital São Marcos, Braga, Portugal

\section{Key Words}

Dural sinus thrombosis - Admission delay ·

Intracranial hypertension

\begin{abstract}
Factors influencing early hospital admission have been described for several stroke types but not for cerebral vein and dural sinus thrombosis (CVT). CVT is more difficult to diagnose than arterial stroke; delay in hospital admission may postpone CVT treatment. The purposes of this study were: (1) to describe the delay between the onset of symptoms and hospital admission of patients with CVT, and (2) to identify the variables that influence that delay. We registered the interval (days) between the onset of symptoms and hospital admission in 91 consecutive patients admitted to 20 Portuguese hospitals between June 1995 and June 1998. We also studied the impact of admission delay on treatments (prescription of anticoagulants and the number of days elapsed between the onset of symptoms and start of anticoagulation and admission). Median admission delay was 4 days. Twenty-two (25\%) patients were admitted within $24 \mathrm{~h}$. Two thirds of the patients were admitted within 7 days and $75 \%$ within 13 days. In multiple logistic regression analysis, admission within $24 \mathrm{~h}$ was positively as-
\end{abstract}

sociated with mental status disorder (delirium or abulia; $\mathrm{OR}=4.59 ; 95 \% \mathrm{Cl}=1.41-14.89)$ and negatively associated with headache $(\mathrm{OR}=0.03 ; 95 \% \mathrm{Cl}=0.00-0.32)$. Presentation as isolated intracranial hypertension was associated with admission delay of more than 4 days (OR $=2.63 ; 95 \% \mathrm{Cl}=0.97-7.14)$. Papilloedema was associated with an admission delay of more than 13 days (OR $=4.69 ; 95 \% \mathrm{Cl}=1.61-13.61)$. There was no association between admission delay and the proportion of anticoagulated patients. The interval between onset of symptoms and start of anticoagulation was shorter in patients admitted earlier ( $p=0.0001$, for either admission within $24 \mathrm{~h}, 4$ or 13 days). There is a considerable delay until the clinical picture associated with CVT is recognised as justifying hospital admission, especially when patients present with symptoms identical to isolated intracranial hypertension syndrome.

Copyright (C) 2005 S. Karger AG, Basel

Factors influencing early hospital referral and admission have been described for several stroke types [1-6], including subarachnoid haemorrhage [7-10], but not for cerebral vein and dural sinus thrombosis (CVT). This type of stroke is far less frequent and has more diverse presenting patterns than arterial stroke, and these factors

\section{KARGER}

Fax +4161306 1234 E-Mail karger@karger.ch www.karger.com
(C) 2005 S. Karger AG, Basel 1015-9770/05/0193-0152\$22.00/0

Accessible online at: www.karger.com/ced
José M. Ferro

Centro de Estudos Egas Moniz

Department of Neurology, Hospital Santa Maria

PT-1649-035 Lisboa (Portugal)

Tel./Fax +351 21795 7474, E-Mail jmferro@fm.ul.pt 
Fig. 1. Distribution of the interval (days) between onset of symptoms and hospital admission.

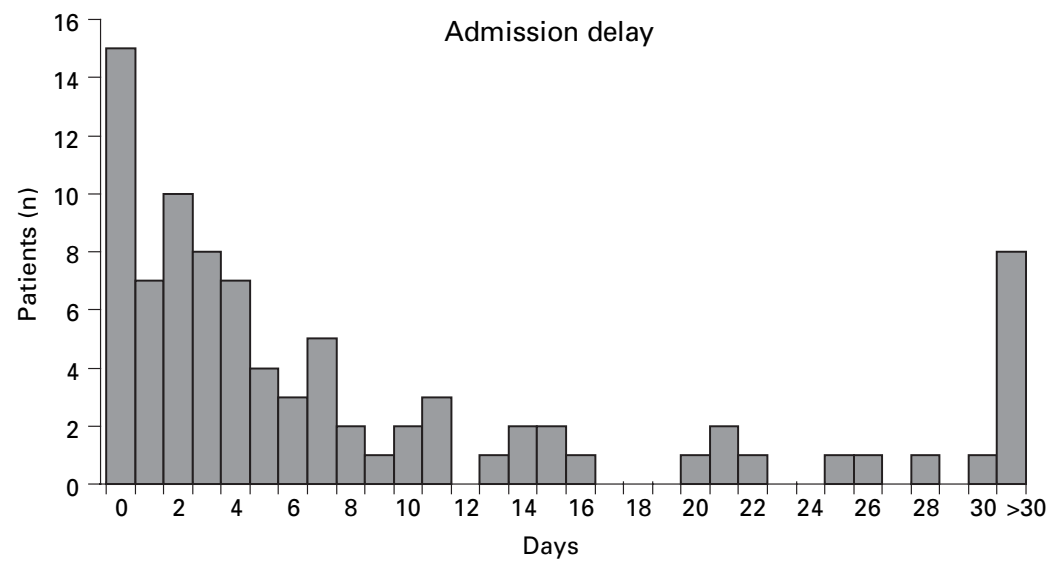

complicate its recognition and delay clinical suspicion and diagnosis. On the other hand CVT can be readily diagnosed using modern neuroimaging techniques, either $\mathrm{MRI} / \mathrm{MR}$ venography or CT venography. Intravenous or subcutaneous anticoagulation improve the prognosis of acute CVT [11]. Local thrombolysis is selectively used in experienced centres in severe cases [12]. The clinical course of CVT is often unpredictable and in many patients the clinical picture worsens after diagnosis [13]. Delay in hospital admission and of CVT diagnosis postpones appropriate treatment.

The purpose of this study was twofold: (1) to describe the delay between the onset of symptoms and hospital admission of patients with CVT, and (2) to identify the variables that influence that delay, i.e. to test the hypothesis that more severe clinical presentation patterns have a shorter admission delay.

\section{Method}

We registered the interval (days) between the onset of symptoms and hospital admission in 91 consecutive patients admitted to 20 Portuguese hospitals between June 1995 and June 1998 (all patients were also included in the VENOPORT study [14]). All cases were confirmed by intra-arterial or MRI/MR venography or angiography.

Possible explanatory variables of the admission delay included were centre, age and gender, location of the occluded sinus/vein, parenchymal lesion on admission CT/MRI (infarct/oedema and haemorrhage), symptoms and signs at admission, presentation syndromes (isolated intracranial hypertension, defined as any combination of headache, vomiting and papilloedema with or without VI nerve palsy vs. other presentation syndromes) and risk factors for CVT.

Admission for Dural Sinus Thrombosis
We analysed the impact of admission delay on the prescription of anticoagulants and the number of days elapsed between the onset of symptoms and start of anticoagulation and between admission and start of anticoagulation. Outcome was assessed with the modified Rankin Scale (mRS) [15] at hospital discharge (median 18 days) and at the end of follow-up (median 22 months; range 3-36 months) [16]. Unfavourable outcome was defined as an mRS 3-6.

\section{Statistics}

We dichotomised admission delay according to the median of the distribution. A second subgroup division contrasted the quartiles with the shortest admission delays (ultra-early admission) with those of the remaining patients, and the quartile with the longest (delayed) admission delays with those of the remaining patients. To test for bivariate associations between categorical variables we used $\chi^{2}$ with Yates correction when necessary or Fisher exact test. No correction for multiple testing was performed. To evaluate the association between continuous variables and two conditions of a categorical variable we used t test or median test, depending on the normality of the distribution of the continuous variable. Variables with a trend $(p<0.20)$ to be associated with admission delay on bivariate analysis were entered in a multiple logistic regression, with computation of OR and $95 \%$ CIs.

\section{Results}

Data on admission delay was available for 90 patients. Distribution of admission delay is shown in figure 1. As expected the distribution was skewed, with a median of 4 days. Twenty-two (25\%) patients were admitted within $24 \mathrm{~h}$ and $75 \%$ within 13 days. Two thirds of the patients were admitted within 7 days.

Variables positively and negatively correlated in bivariate analysis with an admission delay of 1 day or less (ultra-early admissions), 4 days or less, and 13 days (de- 
Table 1. Distribution of potential predictors by admission delays

\begin{tabular}{|c|c|c|c|c|c|c|c|c|c|}
\hline & \multicolumn{9}{|c|}{ Admission delay } \\
\hline & \multicolumn{3}{|c|}{$\leq 1$ day } & \multicolumn{3}{|c|}{$\leq 4$ days } & \multicolumn{3}{|c|}{$>13$ days } \\
\hline & $\mathrm{n}$ & $\%$ & $\mathrm{p}$ & $\mathrm{n}$ & $\%$ & $\mathrm{p}$ & $\mathrm{n}$ & $\%$ & $\mathrm{p}$ \\
\hline Male & 4 & 17 & n.s. & 10 & 42 & n.s. & 6 & 25 & n.s. \\
\hline Age $>45$ years & 3 & 16 & n.s. & 7 & 37 & n.s. & 6 & 32 & n.s. \\
\hline \multicolumn{10}{|l|}{ Admission CT/MRI } \\
\hline Infarct/oedema & 9 & 30 & n.s. & 16 & 53 & n.s. & 9 & 30 & n.s. \\
\hline Haemorrhage & 8 & 30 & n.s. & 15 & 56 & n.s. & 8 & 30 & n.s. \\
\hline Any lesion & 10 & 20 & n.s. & 23 & 56 & n.s. & 10 & 24 & n.s. \\
\hline \multicolumn{10}{|l|}{ Symptoms/signs } \\
\hline Isolated intracranial hypertension syndrome & 2 & 6 & 0.004 & 9 & 29 & n.s. & 12 & 39 & 0.02 \\
\hline Headache & 16 & 19 & 0.001 & 41 & 49 & 0.003 & 22 & 27 & n.s. \\
\hline Papilloedema & 5 & 15 & n.s. & 11 & 32 & n.s. & 15 & 44 & 0.001 \\
\hline Stupor/coma & 2 & 20 & n.s. & 7 & 70 & n.s. & 2 & 20 & n.s. \\
\hline Mental status disorder & 9 & 47 & 0.02 & 13 & 68 & n.s. & 3 & 14 & n.s. \\
\hline Motor deficit & 10 & 33 & n.s. & 20 & 67 & n.s. & 6 & 20 & n.s. \\
\hline Seizure & 10 & 34 & n.s. & 17 & 59 & n.s. & 7 & 24 & n.s. \\
\hline Aphasia & 3 & 25 & n.s. & 8 & 67 & n.s. & 1 & 8 & n.s. \\
\hline Cerebral deep venous system thrombosis & 1 & 14 & n.s. & 6 & 86 & n.s. & 1 & 14 & n.s. \\
\hline \multicolumn{10}{|l|}{ Outcome at final follow-up } \\
\hline Death & 2 & 29 & n.s. & 4 & 57 & n.s. & 3 & 43 & n.s. \\
\hline Dependency (mRs 3,4,5) & 0 & 0 & n.s. & 1 & 100 & n.s. & 0 & 0 & n.s. \\
\hline Independent (mRs 2) & 2 & 33 & n.s. & 3 & 50 & n.s. & 1 & 17 & n.s. \\
\hline Complete recovery (mRs 0,1$)$ & 18 & 24 & n.s. & 39 & 52 & n.s. & 18 & 24 & n.s. \\
\hline
\end{tabular}

$\mathrm{n}=$ Number with condition; $\%$ = calculated by dividing the number with the condition and within delay interval by the total number with that condition.

layed admissions are shown in table 1). There was no association between admission delay and centre, location of the occluded sinus/vein, and risk factors for CVT. In logistic regression analysis, admission within $24 \mathrm{~h}$ was positively associated with mental status disorder (delirium or abulia; $\mathrm{OR}=4.59 ; 95 \% \mathrm{CI}=1.41-14.89)$ and negatively associated with headache $(\mathrm{OR}=0.03 ; 95 \% \mathrm{CI}=$ $0.00-0.32$ ). Presentation as isolated intracranial hypertension was associated with admission delay of more than 4 days $(\mathrm{OR}=2.63$; 95\% CI $=0.97-7.14)$. Papilloedema was associated with admission delay of more than 13 days $(\mathrm{OR}=4.69 ; 95 \% \mathrm{CI}=161-13,61)$.

As far as the influence of admission delay on treatment is concerned, there was no association between admission delay and the proportion of anticoagulated patients: 20 anticoagulated out of 22 patients admitted within $24 \mathrm{~h}$ $(91 \%)$ vs. 55/68 admitted later ( $81 \%$; $p=0.27)$; 34 anticoagulated out of 43 patients admitted within 4 days $(79 \%)$ vs. $41 / 47$ admitted later $(87 \%$; $\mathrm{p}=0.30) ; 56$ anticoagulated out of 68 admitted within 13 days (82\%) vs. $19 / 22(86 \% ; p=0.766)$ admitted later. The interval be- tween onset of symptoms and start of anticoagulation was shorter for patients admitted earlier $(p=0.0001$, median test, for either admission within 24 h, 4 or 13 days). However there were no differences in the interval between admission and start of anticoagulation between patients admitted within or after each of those time windows.

\section{Discussion}

In this cohort mean delay between onset of symptoms and hospital admission was 4 days, though with a wide variation range. Presentation as isolated intracranial hypertension and older age were associated with an increased delay in hospital admission. Not surprisingly, anticoagulation was started earlier in patients with early presentation, but the proportion of anticoagulated patients was not influenced by the admission delay.

This is the first systematic study to describe and analyse the admission delay of CVT patients; however, it has some limitations. The onset of symptoms in CVT can be 
gradual, the precise day of onset being difficult to define and influenced by recall bias. After hospital admission it may take a few days to reach the diagnosis and this will further delay starting appropriate treatment. Unfortunately we did not record the day of the confirmation of the diagnosis. However the delay in starting anticoagulation after admission was similar in all patients (independent of ultra-early, early or late admission). This is an indirect indication that the time to diagnosis after admission was not influenced by admission delay. We also did not collect information on medical encounters previous to hospital admission or on the patients' own view of their health problem.

A quarter of the patients were admitted on the day of symptoms onset and two thirds were admitted within a reasonable interval of 1 week. Only $15 \%$ entered hospital more than 3 weeks after the first symptoms. Factors influencing early presentation can be related to the patient, the disease or the health care organisation; these three factors contribute to admission delays in CVT patients. The wide variation in admission delays reflects the patients', their proxies' and physicians' difficulties in recognising the seriousness of the condition. Presentation as isolated intracranial hypertension syndrome and older age were independent predictors of delayed admission. When experiencing a rather common symptom (such as headache), patients may delay seeking medical attention and physicians may be reluctant to order an MRI as firstline imaging procedure. The relative rarity of CVT makes it less likely to be included in the differential diagnosis list of a general practitioner or emergency physician examining a patient complaining of a headache. They probably do not perform fundoscopy routinely. The finding of papilloedema may trigger admission, but papilloedema may take days to develop. Conceivably, the need to perform MRI to confirm the diagnosis delays the diagnosis of CVT because MRI is less readily available and more costly than CT.

Admission delay had no impact on the prescription of anticoagulants, although patients who came earlier also started treatment sooner. Breteau et al. [17] registered the delay (median 5 days) between onset of symptoms and starting heparin in a series of 55 CVT patients. Delay in starting heparin had an influence on outcome. In Einhäupl et al.'s [18] trial heparin was started a mean of 32.5 days after the initial symptoms, while in the nadroparin trial [19] the mean delay from symptoms onset to randomisation was 10 days. In a systematic review of thrombolysis in CVT [12], the outcome of patients treated before and 1 week after onset was similar. In their series of
18 CVT patients Rondepierre et al. [20] also found no association between admission delay and diagnosis and outcome. This is in accordance with our previous finding that admission delay was not associated with a worse outcome $[14,15]$. One factor contributing to this counterintuitive result is the very early admission of patients with more dramatic and severe clinical presentations who have a less favourable prognosis. Therefore there is currently no convincing evidence that delay in establishing the diagnosis or in starting treatment influences outcome.

The results of this investigation must be confirmed in a larger sample, preferably multinational, to decrease local practice bias. This is particularly important for our finding that admission delay does not seem to impact on outcome. If possible, other factors should be investigated, including the intra-hospital delay in diagnosis and factors leading the patient to look for medical attention, medical contacts and diagnosis before CVT confirmation.

Our results have some implications for practice. There is considerable delay in recognising that the clinical picture associated with CVT is serious enough to justify hospital admission. Headaches are the most frequent symptom of CVT, but CVT presenting as headache or intracranial hypertension syndrome is more difficult to diagnose. CVT should be considered a potential diagnosis in patients presenting new-onset headaches, or headaches of a type or severity different to their usual ones. Early recognition of CVT hastens commencement of appropriate treatment and also speeds the search for treatable, potentially health-threatening risk factors and associated conditions. At present, MRI must be performed to confirm CVT. D-dimers can be used as a screening tool for CVT [21], although there is a possibility of false negatives [22]. A sensible sequence to exclude CVT in patients presenting with headaches would be to perform CT and Ddimers in all patients and to request MR only for those with direct or indirect signs of CVT on CT and/or high D-dimers titers. It remains to be seen which strategy is more cost effective: using this diagnostic sequence or referring patients with such types of headaches directly for MRI to screen for CVT (and other intracranial diseases).

\section{Acknowledgements}

This study was supported by grants from the Fundação para a Ciência e Tecnologia (P/SAU/10248/1998) e Associação para o Desenvolvimento da Investigação na Doença Vascular Cerebral. 


\section{References}

1 Davalos A, Castillo J, Martinez-Vila E: Delay in neurological attention and stroke outcome. Cerebrovascular Diseases Study Group of the Spanish Society of Neurology. Stroke 1995;26: 2233-2237.

2 Jorgensen HS, Nakayama H, Reith J, Raaschou HO, Olsen TS: Factors delaying hospital admission in acute stroke: The Copenhagen Stroke Study. Neurology 1996;47:383-387.

3 Wester P, Radberg J, Lundgreen B, Peltonen $\mathrm{M}$ : Factors associated with delayed admission to hospital and in-hospital delays in acute stroke and TIA. A prospective, multicenter study. Stroke 1999;30:40-48.

4 Wester P, Radberg J, Lundgren B, Peltonen M: Factors associated with delayed admission to hospital and in-hospital delays in acute stroke and TIA: A prospective, multicenter study. Seek-Medical-Attention-in-Time Study Group. Stroke 1999;30:40-48.

5 Lacy CR, Suh DC, Bueno M, Kostis JB: Delay in presentation and evaluation for acute stroke. Stroke Time Registry for Outcomes Knowledge and Epidemiology (S.T.R.O.K.E.). Stroke 2001;32:63-69.

6 Nedeltchev K, Arnold M, Brekenfeld C, Isenegger J, Remonda L, Schroth G, Mattle HP: Pre- and in-hospital delays from stroke onset to intra-arterial thrombolysis. Stroke 2003;34: 1230-1234.

7 Kassell NF, Kongable GL, Torner JC, Adams HP, Mazuz H: Delay in referral of patients with ruptured aneurysm to neurosurgical attention. Stroke 1985;16:587-594.

8 Schievink WI, Werf DJM, Hageman LM, Dreissen JJR: Referral pattern of patients with aneurismal subarachnoid hemorrhage. Surg Neurol 1988;29:367-371.
9 Ferro JM, Lopes J, Melo TP, Oliveira V, Crespo M, Campos JG, Trindade A, Antunes JL: Investigation into the causes of delayed diagnosis of subarachnoid hemorrhage. Cerebrovasc Dis 1991;1:160-164.

10 Edner G, Ronne-Engstrom E: Can early admission reduce aneurysmal rebleeds? A prospective study on aneurysmal incidence, aneurysmal rebleeds, admission and treatment delays in a defined region. Br J Neurosurg 1991;5: 601-608.

11 Stam J, de Bruijn SFTM, DeVeber G: Anticoagulation for cerebral sinus thrombosis. Cochrane Database Syst Rev 2002(4): CD002005.

12 Canhão P, Falcão F, Ferro JM: Thrombolytics for cerebral sinus thrombosis. A systematic review. Cerebrovasc Dis 2003; 15:159-166.

13 Crassard I, Canhão P, Ferro JM, Bousser MG, Barinagarrementeria F, Stam J: Neurological worsening in the acute phase of cerebral venous thrombosis in ISCVT (International Study on Cerebral Venous Thrombosis). Cerebrovasc Dis 2003;15(suppl 4):60.

14 Ferro JM, Correia M, Pontes C, Baptista MV, Pita F for the Cerebral Venous Thrombosis Portuguese Collaborative Study Group (VENOPORT): Cerebral vein and dural sinus thrombosis in Portugal: 1980-1998. Results of the VENOPORT study. Cerebrovasc Dis 2001;11:177-182.

15 Bamford JM, Sandercock PA, Warlow CP, Slattery J: Interobserver agreement for the assessment of handicap in stroke patients. Stroke 1989;20:828.
16 Ferro JM, Lopes MG, Rosas MJ, Ferro MA, Fontes $\mathrm{J}$ for the Cerebral Venous Thrombosis Portuguese Collaborative Study Group (VENOPORT): Long-term prognosis of cerebral vein and dural sinus thrombosis. Results of the VENOPORT study. Cerebrovasc Dis 2002;13: 272-278.

17 Breteau G, Mounier-Vehier F, Godefroy O, Gauvrit J-L, Mackowiak-Cordoliani M-A, Girot $\mathrm{M}$, Bertheloot $\mathrm{D}$, Hénon $\mathrm{H}$, Lucas $\mathrm{C}$, Leclerc X, Fourrier F, Pruvo JP, Leys D: Cerebral venous thrombosis. Three-year clinical outcome in 55 consecutive patients. J Neurol 2003;250:29-35.

18 Einhäupl KM, Villringer A, Meister W, Mehraein S, Garner C, Pellkofer M, Haberl RL, Pfister H-W, Schmiedek P: Heparin treatment in sinus venous thrombosis. Lancet 1991;338: 597-600.

19 De Bruijn SFTM, Stam J, for the Cerebral Venous Thrombosis Study Group: Randomised, placebo-controlled trial of anticoagulant treatment with low-molecular-weight heparin for cerebral sinus thrombosis. Stroke 1999;30: 484-488.

20 Rondepierre P, Hamon M, Leys D, Lederc X, Mournier-Vehrer F, Godefroy O, Janssens E, Pruvo JP: Thromboses veineuses cérébrales: étude de l'évolution. Rev Neurol 1995;151: 100-104.

21 Lalive PH, de Moerloose P, Lovblad K, Sarasin FP, Mermillod B, Sztajzel: Is measurement of D-dimer useful in the diagnosis of cerebral venous thrombosis? Neurology 2003;61:10571060 .

22 Talbot K, Wright M, Keeling D: Normal Ddimer levels do not exclude the diagnosis of cerebral venous sinus thrombosis. J Neurol 2002;249:1603-1604. 
Copyright: S. Karger AG, Basel 2005. Reproduced with the permission of S. Karger AG, Basel. Further reproduction or distribution (electronic or otherwise) is prohibited without permission from the copyright holder. 